University of Nebraska - Lincoln

DigitalCommons@University of Nebraska - Lincoln

Roman L. Hruska U.S. Meat Animal Research

U.S. Department of Agriculture: Agricultural Center

Research Service, Lincoln, Nebraska

2012

\title{
Sampling and aging effects on beef longissimus color stability measurements
}

D. A. King

USDA-ARS, andy.king@usda.gov

S. D. Shackelford

USDA-ARS

Norasak Kalchayanand

USDA Meat Animal Research Center, norasak.kalchayanand@ars.usda.gov

T. L. Wheeler

USDA-ARS, tommy.wheeler@ars.usda.gov

Follow this and additional works at: https://digitalcommons.unl.edu/hruskareports

King, D. A.; Shackelford, S. D.; Kalchayanand, Norasak; and Wheeler, T. L., "Sampling and aging effects on beef longissimus color stability measurements" (2012). Roman L. Hruska U.S. Meat Animal Research Center. 412.

https://digitalcommons.unl.edu/hruskareports/412

This Article is brought to you for free and open access by the U.S. Department of Agriculture: Agricultural Research Service, Lincoln, Nebraska at DigitalCommons@University of Nebraska - Lincoln. It has been accepted for inclusion in Roman L. Hruska U.S. Meat Animal Research Center by an authorized administrator of DigitalCommons@University of Nebraska - Lincoln. 


\title{
Sampling and aging effects on beef longissimus color stability measurements ${ }^{1}$
}

\author{
D. A. King, ${ }^{2}$ S. D. Shackelford, N. Kalchayanand, and T. L. Wheeler \\ USDA $^{3}$-ARS, Roman L. Hruska U.S. Meat Animal Research Center, Meat Safety and \\ Quality Research Unit, Clay Center, NE 68933-0166
}

\begin{abstract}
The present study was conducted to determine the repeatability of color stability measurements and to evaluate relationships among color stability data collected under differing sampling and aging protocols. Beef (Bos taurus) carcasses ( $\mathrm{n}=$ 100) were selected at grading in a commercial facility, after which a LM steak was removed from the 13th rib of each carcass and immediately placed in simulated retail display. Steaks were removed from the remainder of each loin after 14 (duplicate) and $35 \mathrm{~d}$ of aging and placed in display. Color attributes $\left[\mathrm{L}^{*}, \mathrm{a}^{*}, \mathrm{~b}^{*}\right.$, hue angle, chroma, $\mathrm{K} / \mathrm{S}_{572} / \mathrm{K} / \mathrm{S}_{525}$, and overall color change $(\Delta \mathrm{E})]$ were determined on $\mathrm{d} 0,1,4,7$, and 11 of display. Duplicate $14-\mathrm{d}$ aged steaks differed $(P<0.05)$ initially with regard to $\mathrm{L}^{*}, \mathrm{~b}^{*}$, hue angle, chroma, $\mathrm{K} /$ $\mathrm{S}_{572} / \mathrm{K} / \mathrm{S}_{525}$, and $\Delta \mathrm{E}$. However, changes in these attributes during display were equivalent in the duplicate steaks. Furthermore, repeatability estimates were high for all attributes, particularly when measured late in the display period ( $R=0.55$ to 0.97 on $\mathrm{d} 4,7$, and 11 of display). Differences in the trends associated with color change of steaks removed from the carcass after grading and those aged for $14 \mathrm{~d}$ were generally insignificant. Changes in color attributes of steaks aged for 35
\end{abstract}

$\mathrm{d}$ before simulated retail display generally were much more rapid than those obtained after grading or those aged for $14 \mathrm{~d}$. Despite differences in the rate of discoloration during simulated retail display, color attributes were moderately to highly correlated $(P<0.05)$ between aging treatments, though the degree of correlation between attributes varied across days of display. In steaks collected after grading and those aged for 14 $\mathrm{d}$, the greatest correlation was observed in the latter part of the display period with coefficients ranging from 0.61 to 0.94 on $\mathrm{d} 4,7$, and 11 of display. The greatest correlation between steaks aged for $14 \mathrm{~d}$ and those aged for $35 \mathrm{~d}$ were detected in the middle portion of the display period, presumably because many steaks aged for $35 \mathrm{~d}$ had reached an ultimate level of discoloration by $\mathrm{d} 11$ of display with correlation coefficients ranging from 0.51 to 0.95 on $\mathrm{d} 4$ and 7 of display. Thus, these results indicate that color stability data is highly repeatable and that, although aging impacts color-life, animal variation is consistent across aging times. Furthermore, steaks obtained from carcasses after grading can provide color stability evaluations applicable to steaks from aged subprimals.

Key words: aging, beef, color stability, meat color, repeatability, sampling

(C) 2012 American Society of Animal Science. All rights reserved.

This document is a U.S. government work and is not subject to copyright in the United States.

\footnotetext{
${ }^{1}$ Mention of trade names or commercial products in this publication is solely for the purpose of providing specific information and does not imply recommendation or endorsement by the U.S. Department of Agriculture The authors are grateful to Patty Beska, Kristen Ostdiek, Kathy Mihm, and Pat Tammen of the U.S. Meat Animal Research Center for their assistance in the execution of this experiment and to Marilyn Bierman of the U.S. Meat Animal Research Center for her secretarial assistance.

${ }^{2}$ Corresponding author: andy.king@ars.usda.gov

${ }^{3}$ USDA is an equal opportunity provider and employer.

Received November 2, 2011.

Accepted March 23, 2012.
}

J. Anim. Sci. 2012.90:3596-3605 doi:10.2527/jas2011-4871

\section{INTRODUCTION}

Previous results from our laboratory have identified inherent variation in lean color stability in addition to environmental effects which, to some extent, are genetically regulated (King et al., 2010, 2011a,b). Thus, investigation of the genetic $\times$ environment interactions regulating lean color stability, as well as the development of non-invasive technology to predict lean color stability as beef carcasses are presented for grading, is warranted. 
In such studies, data must be collected on numerous samples in a manner representative of commercial conditions and must be repeatable. Postmortem aging varies widely across the industry, with product available at retail outlets after aging times from 3- to 70-d postmortem (Voges et al., 2007). Postmortem aging has been reported to affect the biochemical processes determining lean color stability (Ledward, 1985; Feldhusen et al., 1995; Tang et al., 2005), though few investigations have compared aging times long enough to be relevant to current commercial practices. Our protocols to collect tenderness data for genomics and tenderness prediction studies involve removing a steak from the 13th rib of each carcass after grading, which is subsequently aged until $14 \mathrm{~d}$ postmortem. By measuring color stability during aging, our genomics research could be expanded to lean color stability at minimal cost.

Objectives of the present experiment were to evaluate the repeatability of color stability measurements, as well as to determine whether color stability measurements collected under differing sampling and aging protocols produced results that are consistent with those resulting from other protocols. Furthermore, we investigated relationships between lean color stability data obtained from steaks that had been aged for 14 or $35 \mathrm{~d}$ before simulated retail display. Finally, color stability assessments on steaks removed from carcasses after grading were compared with those from steaks from subprimals aged in vacuum packages before being placed in simulated retail display.

\section{MATERIALS AND METHODS}

Animal care and use approval was not obtained for this experiment because samples for this experiment were acquired postmortem from a federally-inspected commercial processing facility.

Carcasses $(n=100)$ were selected from a commercial processing facility as they were presented for grading at approximately $96 \mathrm{~h}$ postmortem. Carcasses (U.S. Choice) were selected across numerous production lots to have normal LM meat color and marbling scores between Small ${ }^{00}$ and Small ${ }^{50}$. After grading, carcasses were placed on a stationary rail where a $2.54-\mathrm{cm}$-thick steak was removed from the strip loin (13th rib) of the left side of each carcass. Care was taken to ensure that the freshly cut surface of the steak (posterior surface) was not touched by the investigators or other objects. Steaks were placed in plastic trays in an insulated container with ice-packs. The plastic trays were deeper than the thickness of the steak, and layers of trays were separated with cardboard so that the freshly-cut, posterior surface of the steak was not contacted by other steaks or trays. Steaks were transported to the U.S. Meat Animal
Research Center (USMARC) meat laboratory, overwrapped, and placed in simulated retail display. The remaining portion of the strip loin was vacuum packaged after fabrication and transported, under refrigeration, to the USMARC meat laboratory. At $14 \mathrm{~d}$ postmortem, the vacuum packages were opened and a 1.27 -cm-thick face cut was removed from the anterior aspect and used for myoglobin and $\mathrm{pH}$ determination. Then two $2.54-\mathrm{cm}-$ thick steaks were removed, overwrapped, and placed in simulated retail display so that the most anterior surface of each steak was exposed to lights during display. Ideally, repeatability would be determined by measuring the same experimental unit multiple times. In the case of steaks in simulated retail display, this is not possible. Thus, adjacent steaks were used to minimize potential location effects for repeatability estimates. The remaining strip loin was re-vacuum packaged (3-Mil vacuum bags, Prime Source, Kansas City, MO; oxygen transmission rate $=0 \mathrm{cc} \cdot 100 \mathrm{~cm}^{-2} \cdot 24 \mathrm{~h}^{-1}$ ) and stored for an additional $21 \mathrm{~d}$ until $35 \mathrm{~d}$ postmortem. After the additional aging, the packages were opened and, after removing a $1.27-\mathrm{cm}$-thick slice, a steak was cut and placed in simulated retail display.

\section{Simulated Retail Display}

Steaks were placed on polystyrene trays with soaker pads and overwrapped with oxygen-permeable polyvinylchloride film (Stretchable meat film 55003815; Prime Source, St. Louis, MO; oxygen transmission rate $=1.4 \mathrm{~mL} \cdot \mathrm{cm}^{-2} \cdot 24 \mathrm{~h}^{-1}$ at $\left.23^{\circ} \mathrm{C}\right)$. Steaks were placed under continuous fluorescent lighting (color temperature $=3500 \mathrm{~K}$; color rendering index $=86 ; 32 \mathrm{~W}$ T8 Ecolux bulb, model F32T8/SPX35 GE; GE Lighting, Cleveland, $\mathrm{OH}$ ), and light intensity at the meat surface was approximately 2000 lux. Display was conducted in a refrigerated room $\left(1^{\circ} \mathrm{C}\right)$, and no temperature fluctuations associated with defrost cycles were encountered.

Steaks cut after aging were allowed to bloom for at least $2 \mathrm{~h}$ after being packaged before color measurements were taken. For steaks removed from the carcass after grading, initial color variables were measured approximately $4 \mathrm{~h}$ after being removed from the carcass. This additional bloom time was due to the time required to transport the steaks from the packing plant to our meat laboratory. Instrumental color readings were taken on each steak on d $0,1,4,7$, and 11 using a Hunter Miniscan XE Plus colorimeter (HunterLab, Reston, VA) with a 25-mm port. The colorimeter was set to collect spectral data with Illuminant $\mathrm{A}$ and a $10^{\circ}$ observer. Commission Internationale de l'Éclairage (CIE) lightness $\left(\mathrm{L}^{*}\right)$, redness $\left(a^{*}\right)$, and yellowness $\left(b^{*}\right)$ color-space values were reported as the average of duplicate readings taken on each steak. Chroma (color intensity; also known as satu- 
ration index) was calculated as: $\left[\left(\mathrm{a}^{* 2}+\mathrm{b}^{* 2}\right)^{0.5}\right]$. Hue angle (redness) was calculated as: [Arctangent $\left(\mathrm{b}^{*} / \mathrm{a}^{*}\right) \times$ $180 / 3.142]$. Overall color change $(\boldsymbol{\Delta E})$ was calculated as $\left(\Delta \mathrm{L}^{* 2}+\Delta \mathrm{a}^{* 2}+\Delta \mathrm{b}^{* 2}\right)^{0.5}$, where $\Delta \mathrm{L}^{*}, \Delta \mathrm{a} *$, and $\Delta \mathrm{b}^{*}$ are the difference between $\mathrm{d} 0$ and $\mathrm{d} 1,4,7$, and 11 values for $\mathrm{L}^{*}, \mathrm{a}^{*}$, and $\mathrm{b}^{*}$, respectively. Additionally, spectral data were used to calculate $\mathrm{K} / \mathrm{S}_{572} / \mathrm{K} / \mathrm{S}_{525}$ ratios to estimate accumulation of metmyoglobin as described by Hunt et al. (1991).

\section{pH and Myoglobin Concentration}

Myoglobin concentration and $\mathrm{pH}$ were measured in duplicate on 2 different occasions to test repeatability of these measurements. The $1.27-\mathrm{cm}$-thick slice removed from each strip loin before the 14-d aged steaks were cut was trimmed free of external fat and epimysium, diced, and pulverized in liquid nitrogen to produce a homogenous powder. Muscle $\mathrm{pH}$ was determined as prescribed by Bendall (1973). Duplicate 2.5-g samples were homogenized in 10 volumes of a $5-\mathrm{m} M$ iodoacetate, $150-\mathrm{m} M \mathrm{KCl}$ solution $(\mathrm{pH}=7.0)$. Homogenates were allowed to rest for a minimum of $1 \mathrm{~h}$ at room temperature, mixed via vortexing, and $\mathrm{pH}$ was measured using a semi-micro combination electrode (Corning Inc., Corning, NY) attached to a Corning $125 \mathrm{pH}$ meter.

Myoglobin was extracted and quantified following the method described by Warris (1979) as modified by Hunt et al. (1999). Briefly, duplicate 2.5-g samples were homogenized in 10 volumes of $40-\mathrm{m} M$ potassium phosphate buffer $(\mathrm{pH}=6.8)$. Homogenates were held on ice for $1 \mathrm{~h}$ to allow complete pigment extraction before centrifugation $(15,000 \times \mathrm{g})$ for $30 \mathrm{~min}$ at $4^{\circ} \mathrm{C}$. Supernatant $(1.5 \mathrm{~mL})$ was syringe filtered (Nalgene $0.45 \mu \mathrm{m}$, surfactant-free cellulose acetate membrane; Thermo Fisher Scientific, Rochester, NY) into a 4-mL cuvette with $1 \mathrm{~mL}$ of $40-\mathrm{m} M$ phosphate buffer and 0.5 $\mathrm{mL}$ sodium hydrosulfite $(10 \mathrm{mg} / \mathrm{mL})$. Absorbance spectra from 400 to $700 \mathrm{~nm}$ were scanned on each sample using a DU 640 spectrophotometer (Beckman Coulter, Inc, Fullerton, CA). Once samples were verified to be in the reduced state (absorbance peak within $2 \mathrm{~nm}$ of 433), extracted pigment concentration was calculated using the absorbance at $433 \mathrm{~nm}$, a molar extinction coefficient of $114,000 \cdot M^{-1} \cdot \mathrm{cm}^{-1}$, the molecular weight of myoglobin $(16,800)$, and the appropriate dilution factor.

\section{Aerobic Plate Counts and Lactic Acid Bacteria Counts}

Aerobic and lactic acid bacteria counts were determined on the steaks aged for $14 \mathrm{~d}$ before simulated retail display to ensure that the discoloration observed during the experiment was not the result of microbial contamination. When the first of the 2 replicate steaks was cut, the posterior (bottom) surface was swabbed $\left(10 \mathrm{~cm}^{2}\right)$ with a sterile cotton swab (Puritan Medical Products, Guilford, ME) moistened with maximum recovery diluents (MRD; Remel, Lenexa, KS). Care was taken so that this surface did not contact any surface other than the knife before being swabbed, and that this surface was placed directly on the foam tray immediately after swabbing. At the conclusion of display (d 11), the anterior (top) surface of the second steak was swabbed in the same manner. Thus, the surfaces sampled on $\mathrm{d} 0$ and 11 of display represented both sides of the knife cut.

After sampling, the cotton swab was placed into 2 $\mathrm{mL}$ of MRD and mixed for $1 \mathrm{~min}$ via vortexing. One milliliter of the mixed sample was enumerated on petrifilm aerobic count plate (3M Microbiology, St. Paul, $\mathrm{MN}$ ) and incubated as recommended by the manufacturer. Colonies were counted (colony forming unit, CFU) using a petrifilm plate reader (3M). For lactic acid bacteria counts, an aliquot of $0.5 \mathrm{~mL}$ of the sample was mixed with $0.5 \mathrm{~mL}$ of $2 \times$ concentration of DeMan, Rogosa, Sharpe (MRS) broth (Difco, Becton Dickinson, Sparks, MD), and $1 \mathrm{~mL}$ was enumerated on petrifilm aerobic count plate. Plates were incubated $\left(32^{\circ} \mathrm{C}\right.$ for 48 h) as recommended by the manufacturer, and the colonies were hand counted. All the bacterial counts were transformed and reported as $\log \mathrm{CFU} / \mathrm{cm}^{2}$ values.

\section{Statistical Analysis}

The repeatability of color attributes during simulated retail display was assessed by subjecting duplicate steaks that had been aged for $14 \mathrm{~d}$ from each strip loin to simulated retail display. These data were analyzed as a randomized complete block with repeated measures using the PROC MIXED procedure (SAS Inst. Inc., Cary, NC). The model tested the fixed effects of the steak, day of display, and their interaction. Carcass was included as a random effect. Day of display was modeled with a spatial power covariance structure. Least-squares means were generated for the steak $\times$ day interaction of each trait. Because the shape of the discoloration curves was of primary importance, a second model was fit with the same random effect and covariance structure described above that tested the fixed effect of steak, the linear and quadratic polynomials of display day, and the interaction between the polynomials of display day and steak. Lackof-fit tests were used to determine if cubic effects were needed. Nonsignificant $(P>0.05)$ terms were removed from the model; thus, the simplest regression equations describing the changes in each color trait and the relationship between the duplicate steaks are presented. Furthermore, variance component estimates were calculated separately for each color attribute on each day of display using the PROC VARCOMP procedure of SAS. 
Repeatability was calculated as (carcass $\sigma^{2}+$ steak location $\left.\sigma^{2}\right) /\left(\right.$ carcass $\sigma^{2}+$ steak location $\sigma^{2}+$ error $\sigma^{2}$ ).

The effects of aging were determined by comparing the color attributes of the steaks collected after grading, steaks aged for $35 \mathrm{~d}$, and the mean of the duplicate steaks aged for $14 \mathrm{~d}$ using the previously described approach. When the regression analysis indicated that separate intercepts and/or $\beta$-coefficients were required to describe the color change in steaks aged for different time periods, linear orthogonal contrasts were used to determine if the intercepts or $\beta$-coefficients associated with color change of steaks from the 3 aging and sampling treatments differed from one another. When testing mean differences at a given time of display was deemed necessary, the mean was projected for each equation at the given time point, and differences were tested using estimate statements. A significance level of 0.05 was used for all judgments of statistical significance. Pearson correlation coefficients were obtained for color attributes between aging treatments on each day of display using the PROC CORR procedure of SAS.

\section{RESULTS AND DISCUSSION}

Table 1 indicates that aerobic plate counts and lactic acid bacteria counts were low at the initiation of display. Lactic acid bacteria counts did not change $(P>0.05)$ during the display period. Aerobic plate counts increased $(P<$ 0.05 ) during display, but were still low on $\mathrm{d} 11$ of display and were far short of counts that would indicate spoilage $\left(10^{6} \mathrm{CFU} / \mathrm{cm}^{2}\right.$; Ingram and Dainty, 1971). Furthermore, these counts were not correlated to any color variables during display ( $P>0.05$; data not shown). Thus, it can be concluded that microbial contamination did not contribute to the color changes observed in this experiment.

Figure 1 presents the least squares means for the color traits collected on these replicate steaks as well as the regression equations that describe the changes in these traits during simulated retail display. The intercept values for the replicate steaks differed $(P<0.05)$ with regard to $\mathrm{L}^{*}, \mathrm{~b}^{*}$, hue angle, chroma and $\mathrm{K} / \mathrm{S}_{572} / \mathrm{K} / \mathrm{S}_{525}$ values, although the magnitude of these differences were generally small (Figure 1). In contrast, the intercepts for

Table 1. Least-squares means for aerobic plate counts and lactic acid bacteria counts of LM steaks aged for 14 $\mathrm{d}$ before simulated retail display on $\mathrm{d} 0$ and 11 of display

\begin{tabular}{lcc}
\hline \hline Day of display & $\begin{array}{c}\text { Aerobic plate count, } \\
\log \text { CFU/cm }\end{array}$ & $\begin{array}{c}\text { Lactic acid bacteria, } \\
\log \text { CFU/cm }\end{array}$ \\
\hline d 0 & 0.44 & 0.37 \\
d 11 & 1.30 & 0.29 \\
SEM & 0.10 & 0.05 \\
$P>F$ & $<0.001$ & 0.26 \\
\hline
\end{tabular}

$\mathrm{a}^{*}$ values (Figure $1 \mathrm{~B}$ ) and overall color change (Figure $1 \mathrm{G})$ did not differ $(P>0.05)$ between the replicate steaks. Although initial color differed, the $\beta$-coefficients for the regression equations describing the change in the color attributes examined in this study during display did not differ between replicates, indicating the color change during display was equal in the paired steaks.

Trends associated with a*, hue angle, and $\mathrm{K} / \mathrm{S}_{572} / \mathrm{K} /$ $\mathrm{S}_{525}$ during display were characterized by slow changes early in the display period with the rate of change increasing as display time increased (Figure 1). Trends associated with $b^{*}$ (Figure 1C) and chroma (Figure 1E) had a similar delay phase at the beginning of display, a rapid decline phase, and finally, a time of very little change late in the display period. Overall color change increased linearly throughout display (Figure 1G). Changes in $\mathrm{L}^{*}$ values were small, but the decline occurred more rapidly early in the display period than in the later part of the display period (Figure 1A).

Myoglobin concentration and muscle $\mathrm{pH}$ were also measured in duplicate (Table 2), although the duplicate samples were taken from the same steak. After this steak was homogenized, sampling and assays were done on separate days for the replicate samples (Table $2)$. The replicates did not differ with regard to myoglobin concentration $(P=0.96)$. However, $\mathrm{pH}$ did differ between replicate sample $(P<0.05)$, even though this difference was extremely small (0.02 units) and likely not of practical importance.

The mechanism resulting in differences in color between steaks taken in such close proximity (steak surfaces were $2.54 \mathrm{~cm}$ apart) to one another is not clear. However, the differences between the replicate steaks existed at the beginning of display and remained constant throughout the display period. This is supported by the repeatability estimates of color attributes presented in Table 3. Differences between steak locations so close in proximity highlight the need to consider steak location during experimental design. These results indicate that steak locations should be standardized, or when multiple steaks are used from a muscle, blocked across treatments to avoid biased results. Repeatability was high for $\mathrm{L}^{*}$ and hue angle, and $\mathrm{K} / \mathrm{S}_{572} / \mathrm{K} / \mathrm{S}_{525}$ values on all days of display. Values for $\mathrm{a}^{*}, \mathrm{~b}^{*}$, chroma, and $\Delta \mathrm{E}$ were moderate to low in repeatability on $\mathrm{d} 0$ or 1 of display, but were highly repeatable on $\mathrm{d} 4$ and 7 of display. All of the attributes, except $b^{*}$ and chroma, were still highly repeatable on $\mathrm{d} 11$ of display, although the repeatability estimates were somewhat lower for all attributes except $\mathrm{L}^{*}$ on $\mathrm{d} 11$ compared with $\mathrm{d} 7$ values. The increase, and subsequent decrease, in repeatability as the display period progressed may be due to increased variation among carcasses in these traits as display progressed, and then less variation as steaks reached an ul- 

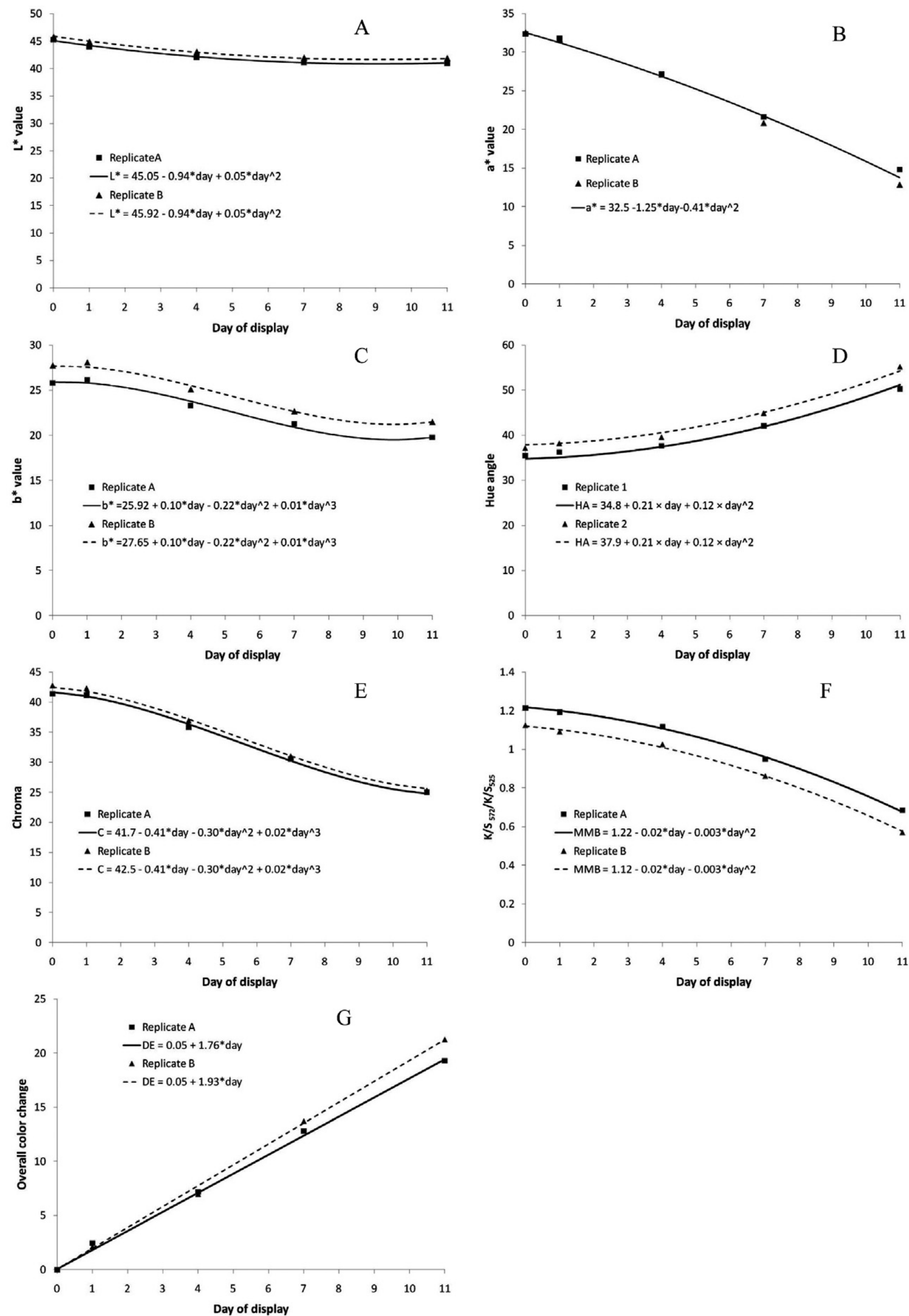

Figure 1. Least-squares means and predicted trends of color attributes of replicate LM steaks during $11 \mathrm{~d}$ of simulated retail display at $14 \mathrm{~d}$ postmortem. $\mathrm{HA}=$ hue angle; $\mathrm{MMB}=$ Metmyoglobin content (estimated by $\mathrm{K} / \mathrm{S}_{572} / \mathrm{K} / \mathrm{S}_{525}$ ratios; $\mathrm{DE}=\Delta \mathrm{E}$ (overall color change). 
Table 2. Least-squares means for myoglobin concentration and $\mathrm{pH}$ of replicate LM samples

\begin{tabular}{lcc}
\hline \hline Item & Myoglobin, $\mathrm{mg} / \mathrm{g}$ & $\mathrm{pH}$ \\
\hline Replicate A & 4.22 & 5.60 \\
Replicate B & 4.22 & 5.58 \\
SEM & 0.07 & 0.005 \\
$P>F$ & 0.96 & $<0.001$ \\
\hline
\end{tabular}

timate amount of discoloration. Measurements for both myoglobin concentration and $\mathrm{pH}$ were highly repeatable. Thus, these results suggest that measurements made with regard to beef color stability during display studies are sufficiently repeatable for use in phenomic and genomic investigations of these traits.

\section{Sampling and Aging Effects on Lean Color Stability}

To efficiently conduct large-scale genetic studies of color stability requires an economical approach. Removing a single steak from a ribbed carcass is a much more economical option than obtaining the entire strip loin. But, removing that steak from the ribbed carcass, shortly after the carcass is graded at 24- to 96-h postmortem, requires that simulated retail display is initiated at a time much earlier postmortem than most retail steaks. Thus, one of our objectives was to assess color stability measurements taken on a LM steak removed from the carcass immediately after grading compared with those taken on a steak removed from a strip loin that had been vacuum packaged and aged until $14 \mathrm{~d}$ postmortem. Furthermore, we assessed the color stability of steaks subjected to prolonged aging ( $35 \mathrm{~d}$ ) being placed in simulated retail display. Fourteen days of aging is the most commonly used aging time for meat tenderness research and provides a basis for comparing meat color research with other meat quality studies. Additionally, the 35-d aging period represents a prolonged aging treatment that is relatively common in commercial practice. The leastsquares means and trend lines describing change in color attributes for steaks from each of the sampling and aging times evaluated are presented in Figure 2.

Of the color attributes evaluated in this study, only $L^{*}$ was not affected $(P>0.05)$ by an aging time $\times$ day of display interaction, and lightness did not differ $(P>0.05)$ across aging times (Figure 2A). Regardless of aging time, lightness decreased through the display, with the greatest decline occurring during the first $4 \mathrm{~d}$ of display, and very small decreases between $\mathrm{d} 4$ and $7 \mathrm{~d}$ of display.

The greatest differences in color changes across aging times were detected in a* (Figure 2B). The intercept for the equation describing the changes in steaks removed from the carcass after grading was greater $(P<0.05)$ than the intercepts for steaks aged for 14 or $35 \mathrm{~d}$ before being placed in display. The linear, quadrat-
Table 3. Repeatability estimates of color traits of beef LM steaks in simulated retail display for $11 \mathrm{~d}$

\begin{tabular}{lccccc}
\hline \hline & \multicolumn{5}{c}{ Day of display } \\
\cline { 2 - 6 } Trait $^{1}$ & 0 & 1 & 4 & 7 & 11 \\
\hline $\mathrm{L}^{*}$ & 0.81 & 0.85 & 0.84 & 0.80 & 0.80 \\
$\mathrm{a}^{*}$ & 0.36 & 0.33 & 0.89 & 0.94 & 0.85 \\
$\mathrm{~b}^{*}$ & 0.58 & 0.57 & 0.74 & 0.75 & 0.55 \\
Hue angle & 0.80 & 0.84 & 0.93 & 0.97 & 0.91 \\
Chroma & 0.44 & 0.38 & 0.83 & 0.89 & 0.66 \\
$\mathrm{~K} / \mathrm{S}_{572} / \mathrm{K}_{\mathrm{N}} \mathrm{S}_{525}$ & 0.70 & 0.73 & 0.85 & 0.97 & 0.89 \\
$\Delta \mathrm{E}$ & - & 0.23 & 0.89 & 0.92 & 0.82 \\
Myoglobin & 0.96 & - & - & - & - \\
$\mathrm{pH}$ & 0.85 & - & - & - & - \\
\hline
\end{tabular}

${ }^{1} \Delta \mathrm{E}=$ overall color change.

ic, and cubic $\beta$-coefficients were different $(P<0.05)$ in the 3 equations describing change in a* values of steaks from the 3 aging treatments evaluated in the present experiment. The trend lines for $\mathrm{a}^{*}$ changes in steaks removed from carcasses after grading and those aged for $14 \mathrm{~d}$ before simulated retail display diverged after $4 \mathrm{~d}$ of display, and a* values were greater $(P<0.05)$ in steaks removed from the carcass after grading than those aged for $14 \mathrm{~d}$ on $\mathrm{d} 7$ and 11 of display; however, the magnitudes of these differences were not large. The decline in $a^{*}$ values was much more rapid in steaks aged for $35 \mathrm{~d}$ than in steaks aged for $14 \mathrm{~d}$ or those obtained after grading between $\mathrm{d} 1$ and 7 of display. After $7 \mathrm{~d}$, changes in $\mathrm{a}^{*}$ in steaks aged for $35 \mathrm{~d}$ were small.

The intercept values for the equations describing $b^{*}$ did not differ across aging times. The linear coefficients were similar $(P>0.05)$ between the $\mathrm{b}^{*}$ equations for steaks obtained after grading and those aged for $35 \mathrm{~d}$, and both differed $(P<0.05)$ from the linear coefficient of the equation for steaks aged for $14 \mathrm{~d}$. The quadratic coefficients differed $(P<0.05)$ across the equations describing $b^{*}$ changes in the 3 treatments. The cubic term of the equation describing $b^{*}$ in steaks removed from the carcass after grading was not different from $0(P=$ $0.34)$. The cubic coefficient for the equation describing changes in $\mathrm{b}^{*}$ of steaks aged for $14 \mathrm{~d}$ differed $(P<0.05)$ from the coefficient for the equation describing $b^{*}$ in steaks aged for $35 \mathrm{~d}$. Compared with steaks collected from the carcasses after grading, $b^{*}$ values of steaks aged for $14 \mathrm{~d}$ were greater $(P<0.05)$ on $\mathrm{d} 1$ and 4 , and lower $(P<0.05)$ on $\mathrm{d} 7$ of display. These differences were small and $b^{*}$ was not different between steaks aged for $14 \mathrm{~d}$ and those obtained after grading on $\mathrm{d} 11$ of display. Compared with the other 2 aging treatments, the decline in $b^{*}$ values was much more rapid in steaks aged for $35 \mathrm{~d}$ between $\mathrm{d} 1$ and 7 of display, with only small changes occurred in $b^{*}$ in steaks aged for $35 \mathrm{~d}$ between $\mathrm{d} 7$ and 11 of display. 

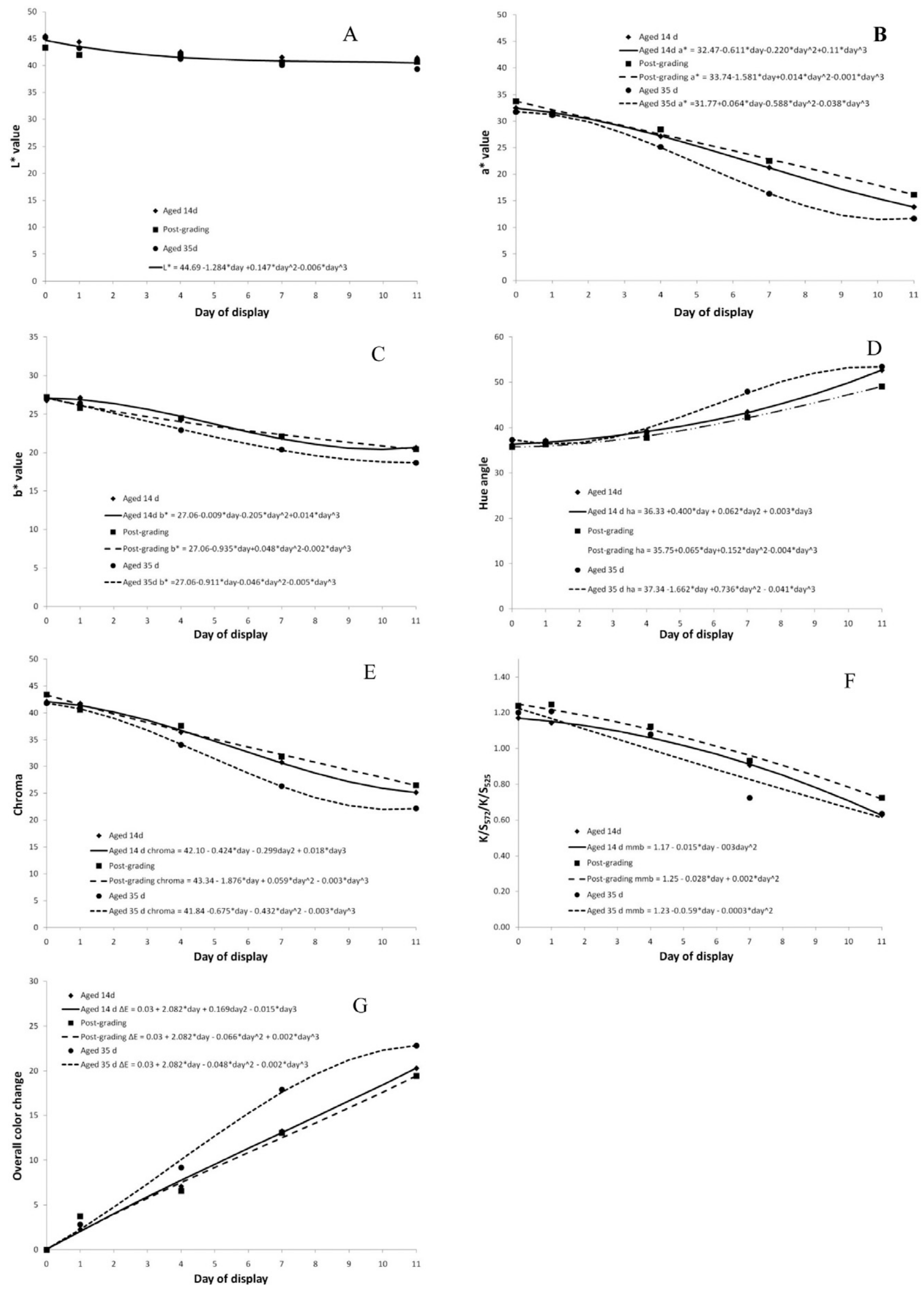

Figure 2. Least squares means and predicted trends with LM steaks removed from the carcass after grading, aged in vacuum for $14 \mathrm{~d}$, or aged in vacuum for $35 \mathrm{~d}$ before being placed in simulated retail display for $11 \mathrm{~d}$. HA = hue angle; MMB $=$ Metmyoglobin content (estimated by K/S $\mathrm{S}_{572} / \mathrm{K} / \mathrm{S}_{525} \mathrm{ratios} ; \mathrm{DE}=\Delta \mathrm{E}$ (overall color change). 
All of the terms for the cubic equations describing the changes in hue angle values were similar $(P>0.05)$ between steaks aged for $14 \mathrm{~d}$ before being placed in simulated retail display and those obtained from carcasses immediately after grading although the cubic term tended $(P=0.16)$ to be different between these 2 groups of steaks (Figure 2D). Thus, hue angle was similar at the beginning of display for these 2 treatments and remained similar until after $7 \mathrm{~d}$ of display, after which hue angle increased at a faster rate in steaks aged for $14 \mathrm{~d}$. Intercepts were similar $(P<0.05)$ between the equations for steaks aged for 14 or $35 \mathrm{~d}$ before being placed in simulated retail display, but all of the $\beta$-coefficients differed $(P<0.05)$ between these 2 equations. Furthermore, all of the terms differed $(P<0.05)$ between the equations describing the changes in hue angle between steaks removed from the carcass after grading and those aged for $35 \mathrm{~d}$ before simulated retail display. Between $\mathrm{d} 4$ and 7 of display, hue angle increased at a much faster rate in steaks aged for $35 \mathrm{~d}$ before being placed in display than in steaks aged for $14 \mathrm{~d}$ or those obtained after grading. After $7 \mathrm{~d}$ of display, the further increases in hue angle of steaks aged for $35 \mathrm{~d}$ occurred at a slower rate.

All parameters for the equations describing change in color intensity (chroma) of steaks removed from the carcasses post-grading were different $(P<0.05)$ from those of the equations describing chroma in steaks aged for 14 or $35 \mathrm{~d}$ postmortem (Figure 2E). Neither the quadratic nor the cubic term of the equation describing chroma in steaks obtained after grading were different ( $P=0.24$ and 0.40 , respectively) from 0 ; thus, the decline in chroma in these steaks can be described as linear, whereas the decline in chroma during display of steaks aged for 14 or $35 \mathrm{~d}$ postmortem is best described as cubic. The cubic parameters were different $(P<0.05)$ between the equations for chroma in steaks aged for 14 or $35 \mathrm{~d}$, but all other parameters were similar between these 2 equations. Thus, chroma was similar between steaks aged for 14 or $35 \mathrm{~d}$ at the initiation of display, but chroma declined more rapidly in steaks aged for $35 \mathrm{~d}$, particularly between $\mathrm{d} 4$ and 7 of display.

At the initiation of display, $\mathrm{K} / \mathrm{S}_{572} / \mathrm{K} / \mathrm{S}_{525}$ intercept values were less $(P<0.05)$ for steaks aged for 14 $\mathrm{d}$ before simulated retail display compared with those removed from the carcass after grading and those aged for $35 \mathrm{~d}$ before being placed in display (Figure 2F). The quadratic models fit the plots of least-squares means of steaks from the post-grading and 14-d aged treatments well, but did not appear to fit the changes in the 35-d steaks. This is likely because the statistical analysis was limited to cubic models and the changes in $\mathrm{K} / \mathrm{S}_{572} / \mathrm{K} /$ $\mathrm{S}_{525}$ of $35 \mathrm{~d}$ aged steaks appeared to be quartic in nature. The regression model fit for 35-d-aged steaks was essentially linear, as the quadratic term was not different from $0(P=0.42)$. Nevertheless, it is clear that metmyoglobin accumulation, as evidenced by $\mathrm{K} / \mathrm{S}_{572} / \mathrm{K} / \mathrm{S}_{525}$ ratios, was more rapid in steaks aged for $35 \mathrm{~d}$ relative to steaks aged for $14 \mathrm{~d}$ or obtained after grading. The linear and quadratic terms of the equations describing the trends associated with $\mathrm{K} / \mathrm{S}_{572} / \mathrm{K} / \mathrm{S}_{525}$ ratios of steaks aged for $14 \mathrm{~d}$ or obtained post-grading differed $(P<$ $0.05)$, although both indicate a delay phase followed by an increasing rate of metmyoglobin accumulation. The trend for metmyoglobin accumulation in steaks removed from the carcass after grading was similar to the trend in steaks aged for $14 \mathrm{~d}$, except that metmyoglobin accumulation was slightly more rapid during the first $4 \mathrm{~d}$ of display, and slightly less rapid between $\mathrm{d} 7$ and 11 of display in steaks removed from the carcass after grading. Ledward (1985) reported that metmyoglobin accumulation followed the pattern of a rapid accumulation phase, followed by a slower phase, and then by another rapid accumulation phase.

By definition, intercepts were equal for the equations describing overall color change in the steaks from the 3 aging treatments examined in the present experiment, and a common linear term was fit for each of the 3 equations (Figure 2G). Moreover, neither the quadratic nor the cubic term of the equations describing color change in steaks obtained from carcasses immediately post-grading and those aged for $14 \mathrm{~d}$ before being placed in simulated retail display were different from $0(P>0.05)$. Thus, the linear increases in $\Delta \mathrm{E}$ were very similar in steaks from these 2 aging treatments. In contrast, the increase in $\Delta \mathrm{E}$ in steaks aged for $35 \mathrm{~d}$ before being placed in simulated retail display was much more rapid between 1 and 7 of display; yet, between $\mathrm{d} 7$ and 11, the rate of overall color change slowed in steaks aged for $35 \mathrm{~d}$.

The longer time between cutting and initial color measurement is likely the cause of differences in initial values of $\mathrm{a}^{*}$, chroma, and $\mathrm{K} / \mathrm{S}_{572} / \mathrm{K} / \mathrm{S}{ }_{525}$ between steaks collected after grading and those aged for $14 \mathrm{~d}$ before being placed in display. We allowed steaks that had been aged before display to bloom for $2 \mathrm{~h}$ before color measurement to allow complete oxygenation. However, Lee et al. (2008) estimated asymptotic values of color attributes during blooming to be beyond those attained during $2 \mathrm{~h}$ of bloom, indicating that complete oxygenation may require longer than $2 \mathrm{~h}$.

The shapes of regression curves describing the change in color attributes of these steaks during display indicate that the prolonged aging time profoundly affected the ability of the muscle to maintain color. This is consistent with the results reported by Hood (1980), which indicate that increased time postmortem was associated with increased metmyoglobin accumulation in beef samples incubated at $25^{\circ} \mathrm{C}$ for $7.5 \mathrm{~h}$. Liu et al. (1996) reported that increasing aging time of LM steaks 
Table 4. Pearson correlation coefficients for color traits of steaks during display that were removed from the carcass after grading ( $4 \mathrm{~d}$ postmortem) or aged for 14 or $35 \mathrm{~d}$ postmortem before being placed in simulated retail display ${ }^{1}$

\begin{tabular}{|c|c|c|c|c|c|c|c|}
\hline Day & $\mathrm{L}^{*}$ & $\mathrm{a}^{*}$ & $\mathrm{~b}^{*}$ & $\mathrm{~K} / \mathrm{S}_{572} / \mathrm{K} / \mathrm{S}_{525}$ & Hue angle & Chroma & $\Delta \mathrm{E}$ \\
\hline \multicolumn{8}{|c|}{ Steaks removed from the carcass after grading to steaks aged for $14 \mathrm{~d}$} \\
\hline $\mathrm{d} 0$ & $0.70^{*}$ & 0.11 & 0.13 & $0.73 *$ & $0.65^{*}$ & 0.06 & - \\
\hline d 1 & $0.71 *$ & 0.08 & 0.18 & $0.79 *$ & $0.74 *$ & 0.05 & $0.22 *$ \\
\hline d 7 & $0.75^{*}$ & $0.88^{*}$ & $0.74 *$ & $0.88 *$ & $0.94 *$ & $0.83 *$ & $0.87^{*}$ \\
\hline d 11 & $0.85^{*}$ & $0.85^{*}$ & $0.65^{*}$ & $0.83^{*}$ & $0.88^{*}$ & $0.77 *$ & $0.78 *$ \\
\hline d 1 & $0.80^{*}$ & $0.30^{*}$ & $0.39 *$ & $0.81 *$ & $0.78^{*}$ & $0.30^{*}$ & $0.33^{*}$ \\
\hline $\mathrm{d} 4$ & $0.82 *$ & $0.89 *$ & $0.71 *$ & $0.95^{*}$ & $0.93 *$ & $0.84 *$ & $0.91 *$ \\
\hline $\mathrm{d} 7$ & $0.70^{*}$ & $0.68^{*}$ & $0.25^{*}$ & $0.73 *$ & $0.83^{*}$ & $0.51^{*}$ & $0.69^{*}$ \\
\hline d 11 & $0.81^{*}$ & $0.46^{*}$ & $0.21 *$ & $0.37 *$ & $0.50 *$ & $0.27 *$ & $0.34 *$ \\
\hline \multicolumn{8}{|c|}{ Steaks removed from the carcass after grading to steaks aged for $35 \mathrm{~d}$} \\
\hline $\mathrm{d} 7$ & $0.71 *$ & $0.64 *$ & $0.28 *$ & $0.66^{*}$ & $0.77 *$ & $0.48 *$ & $0.60^{*}$ \\
\hline d 11 & $0.76^{*}$ & $0.54 *$ & 0.09 & $0.52 *$ & $0.56^{*}$ & $0.22 *$ & $0.36^{*}$ \\
\hline
\end{tabular}

$* P<0.05$.

${ }^{1} \Delta \mathrm{E}=$ overall color change.

from 14 to 28 and from 28 to $56 \mathrm{~d}$ postmortem increased changes in $a^{*}$ and hue angle values, which resulted in reduced color life of steaks. The results of the present experiment were in partial agreement with those of Lindahl (2011), which reported that LM and semimembranosus steaks aged in vacuum for $25 \mathrm{~d}$ had less surface metmyoglobin formation during $5 \mathrm{~d}$ of aerobic dark storage than steaks of the same muscles aged for $5 \mathrm{~d}$ in vacuum. However, Lindahl (2011) also reported steaks that were not aged ( $2 \mathrm{~d}$ postmortem) had greater surface metmyoglobin accumulation than steaks that were aged.

Our primary aim in these comparisons was to determine the degree to which color stability measurements were correlated across sampling and aging conditions. It was important to determine the extent to which color stability evaluated at 1 aging time was indicative of the color stability measured at another aging time. Correlation coefficients comparing the values for color attributes of steaks from each aging time are presented in Table 4. The relationships of color stability measurements taken on steaks removed after grading to those of steaks aged for various times before placement in simulated retail display were of particular importance because using such steaks would greatly increase the efficiency and cost-effectiveness of future genomics and technology research on color stability. When these 3 aging times were compared, all color attributes were highly correlated, except for $\mathrm{a}^{*}, \mathrm{~b}^{*}$, and chroma values measured on $\mathrm{d} 0$ and $\mathrm{d} 1$ of display (Table 4). During later days of display, the correlation for these and all other traits increased as the variation in these traits increased. This is consistent with the changes in correlation of color attributes of various beef muscles to LM color attributes during display (King et al., 2011b). The high degree of correlation between color attributes of steaks aged for $14 \mathrm{~d}$ before being placed in simulated retail display and those removed from the carcass after grading indicates that removing steaks from the carcass after grading and placing them immediately into simulated retail display will provide color stability evaluations that are indicative of the color stability of aged beef.

Color stability was substantially different between steaks aged for $14 \mathrm{~d}$ and those aged for $35 \mathrm{~d}$ before being placed into simulated retail display. As described earlier, a* and chroma were not correlated on $\mathrm{d} 0$ of display between steaks aged for $14 \mathrm{~d}$ and those aged for $35 \mathrm{~d}$ before being placed in simulated retail display (Table 4). However, both a* and chroma were moderately to highly correlated between these ageing treatments on $\mathrm{d} 1,4,7$, and 11 of display. Furthermore, all other color attributes were moderately to highly correlated between steaks aged for $14 \mathrm{~d}$ and those aged for $35 \mathrm{~d}$ before being placed in simulated retail display. Similarly, there were remarkably strong relationships between steaks collected after grading and those aged for $35 \mathrm{~d}$ before being placed in simulated retail display. The high degree of correlation among color attributes of steaks from the investigated sampling and aging treatments indicated that color stability data collected at any given postmortem aging time would be indicative of color stability of steaks from the same carcass aged for a different amount of time. 
These results indicate that color stability measurements are highly repeatable, and, thus, suitable for phenomic studies of this economically important trait. These results also indicate that postmortem aging has profound impacts on retail color-life of beef products, but that animal-to-animal variation is relatively consistent across aging times. Therefore, intervention strategies developed to improve beef lean color stability at shorter aging time also should be effective for product lines using longer aging times. Furthermore, steaks removed from the carcass after grading can be used to reduce cost and increase throughput of studies to develop prediction technology and, at the same time, produce results that can be applied to meat aged in typical manner.

\section{LITERATURE CITED}

Bendall, J. R. 1973. Postmortem changes in muscle. Pages 243-309 in Structure and Function of Muscle. Vol. 2. G. H. Bourne, ed. Academic Press, New York.

Feldhusen, F., A. Warnatz, R. Erdmann, and S. Wenzel. 1995. Influence of storage time on parameters of colour stability of beef. Meat Sci. 40: 235-243.

Hood, D. E. 1980. Factors affecting the rate of metmyoglobin accumulation in pre-packaged beef. Meat Sci. 4:247-265.

Hunt, M. C., J. C. Acton, R. C. Benedict, C. R. Calkins, D. P. Cornforth, L. E. Jeremiah, D. G. Olson, C. P. Salm, J. W. Savell, and S. D. Shivas. 1991. Guidelines for meat color evaluation. Pages 1-17 in Proc. 44th Recip. Meat Conf., Manhattan, KS

Hunt, M. C., O. Sørheim, and E. Slinde. 1999. Color and heat denaturation of myoglobin forms in ground beef. J. Food Sci. 64:847-851.

Ingram, M., and R. H. Dainty. 1971. Changes caused by microbes in spoilage of meats. J. Appl. Bacteriol. 34:21-39.
King, D. A., S. D. Shackelford, L. A. Kuehn, C. M. Kemp, A. B. Rodriguez, R. M. Thallman, and T. L. Wheeler. 2010. Contribution of genetic influences to animal-to-animal variation in myoglobin content and beef lean color stability. J. Anim Sci. 88:1160-1167.

King, D. A., S. D. Shackelford, A. B. Rodriguez, and T. L. Wheeler. 2011a. Effect of time of measurement on the relationship between metmyoglobin reducing activity and oxygen consumption to instrumental measures of beef longissimus color stability. Meat Sci 87:26-32.

King, D. A., S. D. Shackelford, and T. L. Wheeler. 2011b. Relative contributions of animal and muscle effects to variation in beef lean color stability. J. Anim Sci. 89:1434-1451.

Ledward, D. A. 1985. Post-slaughter influences on the formation of metyyoglobin in beef muscles. Meat Sci. 15:149-171.

Lee, M. S., J. K. Apple, J. W. S. Yancey, J. T. Sawyer, and Z. B. Johnson. 2008. Influence of vacuum-aging period on bloom development of the beef gluteus medius from top sirloin butts. Meat Sci. 80:592-598.

Lindahl, G. 2011. Colour stability of steaks from large beef cuts aged under vacuum or high oxygen modified atmosphere. Meat Sci. $87: 428-435$.

Liu, Q, K. K. Scheller, S. C. Arp, D. M. Schaefer, and M. Frigg. 1996. Color coordinates for assessment of dietary vitamin E effects on beef color stability. J. Anim. Sci. 74:106-116.

Tang, J., C. Faustman, T. A. Hoagland, R. A. Mancini, M. Seyfert, and M. C. Hunt. 2005. Postmortem oxygen consumption by mitochondria and its effects on myoglobin form and stability. J. Agric. Food Chem. 53:1223-1230.

Voges, K. L., C. L. Mason, J. C. Brooks, R. J. Delmore, D. B. Griffin, D. S. Hale, W. R. Henning, D. D. Johnson, C. L. Lorenzen, R. J. Maddock, R. K. Miller, J. B. Morgan, B. E. Baird, B. L. Gwartney, and J. W. Savell. 2007. National beef tenderness survey- 2006: Assessment of Warner-Bratzler shear and sensory panel ratings for beef from US retail and foodservice establishments. Meat Sci. 77:357-364.

Warris, P. D. 1979. The extraction of haem pigments from fresh meat. J. Food Technol. 14:75-80. 